\title{
Effectiveness of Psycho - Educational Intervention on The Rate of Attention of Preschool Children with Attention Deficit / Hyperactivity Disorder (ADHD)
}

\author{
Mokhtar Malekpour, Mozhgan Shooshtari* \\ Department of Children with Special Needs, University of Isfahan, Isfahan, Iran \\ *E-mail addresss: mojganshooshtari@yahoo.com
}

\begin{abstract}
The aim of this research was to investigating the effectiveness of psycho-educational interventions on the Rate of attention of preschool children with attention deficit / hyperactivity disorder (ADHD). Statistical population included all Preschool boys with ADHD in Isfahan city, Iran during 2011-2012. The sample of this research was 30 children with ADHD Symptoms. To select this sample, multi-stage random sampling was employed. Then these 30 pre-schoolers were randomly assigned in two groups, (15 children in the experimental group and 15 children in the control group). Research method was experimental with pre and post test design. Research tool, was parent's Conner's questionnaire and clinical interview. Psycho-educational interventions as independent variable was performed on experimental group. Data was analyzed by analysis of Covariance. The results showed that the Psycho - Educational interventions is effective on the rate of attention of preschool children with ADHD $(\mathrm{p}<0 / 001)$. Therefore, psycho-educational intervention is one of appropriate approach for improvement of attention in children with ADHD.
\end{abstract}

Keywords: psycho-educational; attention; intervention; ADHD

\section{INTRODUCTION}

ADHD disorder is one of the most Prevalent problems among children. This disorder influences many aspects of children and families (Biederman and Faraon, 2005). this disorder has impact on social, emotional and cognition performance of children. It can influence parents situation at work and their marriage satisfaction (Kirk et al, 2006).

According to American Psychoatric Association (4 ${ }^{\text {th }}$ edition). ADHD has a set of symptoms accompanied by limitations in attention span which is not coordinated with the child's age level. The age in which the disorder begins is before 5-7 (World Health Organizatio, 1996). The disorder influences 5 to 7 percent of the world population (Kaufman, 2009). The symptoms of the disorder must accure in 2 situations (e.g. school and home). The disorder influences nagatively social and educational performance of the child (Conners, 2002). This disorder, faces the child with many problems including academic performance, cognition and social - emotional. ADHD is one of main factors which accounts for school failure. In relation to this, Wender (1987), stresses that lack of attention impends concentration and increases level of mistakes while doing home work assignments. This 
children are unable to pay attention to rules of games or actions. They have low self-esteem and troubles in getting to a relation with other children. All of these problems cause their families and teacher's negative reactions. This in turn lead to damage of their social relationships.

In terms of etiology there are some theories regarding the cause of ADHD. For example, Kieling et al. (2008), state that this disorder is the most common disorder during childhood. They continue to say that this disorder is a brain complex disorder, which includes many abnormalities in the function of central nerves system. Spencer (2006), addresses that the complexity of this disorder is the result of a series of disorders and it is not a single disorder. In this regard, Castellanos (2008), states that when we look at these disorder we have to consider the interaction of genetic, biological, environmental, neurochemical and nutritional factors. Lin \& Chang (2002), believe that genetic factors contribute 80 present in this disorder.

Since the problems of ADHD lead to other problems for these children, therefore, some kind of intervention has to be down for such children in order to ameliorate these problems. One of these Interventions could be psycho-educational intervention. Psycho-educational intervention suggests the process of psychological evaluation and then intervention planning. This intervention strives to facilitate learning process of the child with special needs (Renolds \& Fletcher, 2000). Today, early intervention programs try to reduce the effects of biological and environmental factors which negatively impact on the child and the like hood of putting him at risk of disability and help the child improve his/her sensory motor functions and speech, cognition, behavioral and social-emotional development. Early intervention programs with regard to the importance of critical periods in learning, early experiences and plasticity of neural tissues, state that children at early years as compared to other stages of life learn more and could have more efficiency.

Therefore, the purpose of this paper is to investigation to what extent, the psychoeducational intervention has effect on attention of children with ADHD.

\section{METHODOLOGY}

The method used in this research was pre test - post test with the control group, multistage random sampling was used to select the samples. The independent variable was psycho-educational early intervention. To do this, out of six educational areas of Isfahan city, two areas were randomly selected. Then of these two area 15 preschool centres were randomly selected.

Then, through conner's questionnaire which were completed by with parents and teachers by parents and clinical interview. 30 students were determined with ADHD symptoms. These 30 students were randomly assigned into two groups. one experimental group with 15 and one control group with 15 students.

Early psycho-educational intervention was employed on experimental group as independent variable. Intervention lasted for 12 sessions. Each session continued for 45 minutes. After the end of training, post test was employed on two groups. Covariance was used to analysis the data. 
Table 1. Diagram of the pre-test - post-test design with control group.

\begin{tabular}{lcccc}
\hline Group & Random selection of subjects & pretest & Independent variable & posttest \\
\hline Experimental & $\mathrm{R}$ & $\mathrm{T} 1$ & $\mathrm{X} 1$ & $\mathrm{~T} 2$ \\
Control & $\mathrm{R}$ & $\mathrm{T} 1$ & - & $\mathrm{T} 2$ \\
\hline
\end{tabular}

\section{1. Summary of psycho-educational intervention sessions}

Session 1: In the session, aim and necessity of psycho-educational early intervention has been explained for parents and Conner's questionaire has been filled by them.

Session 2: Hearing attention - This session has included things like: listening to the sounds, different recorded sounds, eating material sounds (for example chips), shaking material sounds which have been taught to children.

Session 3: Visual attention- see and say game, seeing the pictures and recognizing them, finding he forms according to theire colors and sizes.

Session 4: In this session, the activities which are related to seeing and hearing attention will repeat again.

Session 5: Doing the rhythmical movements by teacher and children.

Session 6: Eye to eye game, this game is to stop impulsivity movements and teach the patience strategy

Session 7: The teacher trains the methods of painting the simple pictures to the children, they first think and then accomplish painting.

Session 8: Children learn not to do anything while some signs are shown by trainer and they must be quite.

Session 9: Self controlling, the children will be taught that what kind of tools they need to do their homework's.

Session 10: Keeping and changing attention, the trainer teach the children to keep attention on the activity and then change it to another activity.

Session11: Building tower, It will be taught to the children how to build towers according to the patterns, looking at the pictures, thinking well, and then painting.

Session 12: Conner's questionnaire is answered by parents.

\section{2. Research tools}

Research tools were: Conner's questionnaire and clinical interview. Conner's questionnaire contains 27 questions, which are answered by children's parents. Scoring is according to Likert's forth scores scale. This tool is used to measure the intensity of ADHD disorder.

In terms of Clinical interview when the child obtained high score in Conner's questionnaire, then he/she was considered for clinical interview. This interview was done to identify more specifically the attention deficit / hyperactivity impulsivity disorder. 


\section{3. Findings}

Means and SDs of experimental and control groups and results of Covariance's analysis are presented in Tables 2 and 3.

Table 2. Means SDs of experimental and control groups (pre test - post test) regarding Conner's questionnaire.

\begin{tabular}{lcccc}
\hline Group & \multicolumn{2}{c}{ before } & intervention & \multicolumn{2}{c}{ after intervention } \\
& Mean & SD & Mean & SD \\
\hline Experimental & 33.4 & 6.2 & 26.8 & 4.3 \\
Control & 31 & 7.3 & 29.3 & 6.4
\end{tabular}

According to Table 2, mean of experimental group has been decreased after intervention which shows the efficacy of intervention in decreasing ADD.

Table 3. Results of covariance analysis of difference between experimental and control groups in Conner's questionnaire.

\begin{tabular}{lcrccccc}
\hline Source & sum of squares & df & mean square & F & sig & Eta & Observed power \\
& & & & & & & \\
\hline Pre & 564.713 & 1 & 564.713 & 67.721 & 0.000 & 0.71 & 100 \\
Group & 298.501 & 1 & 298.501 & 35.480 & 0.000 & 0.63 & 100 \\
Error & 208.761 & 27 & 8.473 & - & - & - & - \\
& & & & & & & \\
\hline
\end{tabular}

The results of Table 3 show that, with regard to pretest scores as a helping variable, the psycho-educational intervention has made difference between the experimental and control groups $(\mathrm{p}<0 / 001)$. The influence range was $(0.63)$. This means that 0.63 percent of posttest variance was related to psycho-educational intervention. Thus, Table 3 shows that, psycho educational intervention has reduced the rate of attention deficit of the children with ADHD.

The aim of current research was to investigated the effectiveness of Psycho-Educational intervention on the rate of attention of preschool children. The result of covariance analysis showed that psycho-educational intervention decreases the rate of ADD $(P=0 / 001)$. In other words, this approach increases the attention of children with ADHD. The result of this study is consistent with studies of Montoya et al. (2011), Toplak et al. (2008), Coleman et al. (2006), Tamm et al. (2005, Rappaport et al. (1998). All of these studies have indicated that psycho-educational Intervention is effective on the rate of attention of Preschool Children with ADHD.

To explain the result of present study, it could be said that early identification and intervention of ADD is central in reducing ADD symptoms and possibly healing theme. Almost all mental health professionals believe that early years are particularly important in later adjustment. This is also true for ADD because early identification and intervention of ADD could impact on decreasing it on one hand and preventing emergence of other problems 
like school failure and difficulty in personal relationships with school personal and the peers, on the other hand.

\section{CONCLUSIONS}

The outcome of this study indicated that psycho-educational intervention accounts for reduction of $\mathrm{ADD}$. This itself has two dimensions: one is psycho and the other one is educational. In psychological point of view, it could be said that psychological approach takes into account the psychological status of the child with ADD and helps the child organize and integrate his psychological characteristics. The educational dimension of this approach assists the child to learn how to react appropriately to environmental stimuli. Therefore, both dimensions of this approach could help child's attention.

\section{Refrences}

[1] Barkley, R. A. (2006). Attention - deficit /hyperactivity disorder: A handbook for diagnosis and treatment. New York: Guilford press.

[2] Biederman, J., Faraone, S. V (2005). A psychometric measure of learning disability predicts educational failure four years later in boys with attention deficit hyperactivity disorder. Journal of Attention Disorders, 4; 220-230.

[3] Castellanos, F. X. (2008). Toward a pathophysiology of attention deficit/ hyperactivity. Clinical Pediatric, 36; 370-383.

[4] Conners, C. K. (2002). Food additives and hyperactive children. New York: Plenum Press.

[5] Daley, D. (2006). Attention Deficit Hyperactivity disorder: A review of the essential facts. Child: Care, Health \& Development, 32; 193-204.

[6] Das Banerjee, T. D., Middleton, F., Faraone. S. V. (2007). Environmental risk factors for attention deficit hyperactivity disorder. Acta Paediatrica, 96; 1269-1274.

[7] Harpin, V. A. (2005). The effect of ADHD on the life of an individual, Their family, and community from preschool to adult life. Archive of disease in childhood. 90; i2-i7.

[8] Kaufman R., Goldberg-Stern H., Shaper A. (2009). Attention -Deficit Disorder and Epilepsy in Childhood: Incidence, Causative relations and Treatment Possibilities. Journal of Child Neurology, 24(6); 727-733.

[9] Kieling C., Goncalves R. R., Tannock R., Castellanos F. X. (2008). Neurobiology of attention in deficit hyperactivity disorder. Child and Adolescent Psychiatric Clinics of North America, 17; 285-307.

[10] Kirk, S. A., Gallagher J. J., Anastasiow N. J., Coleman M. R. (2006). Educating exceptional children. Boston: Houghton Mifflin.

[11] Korkman, M., Kirk, U., \& Kemp, S. (1998). NEPSY: A developmental neuropsychological assessment. San Antonio, TX: The psychological Corporation. 
[12] Leo, M. I., Balestrion, D. M., Phelps, A. R. Kurs-Iasky. M., Chaves-Gnocco. D, Paradise, L. J., Feldman, M. H. (2008). Early histories of school -aged children with attention -deficit hyperactivity disorder. Child development, 6(79); 1853-1868

[13] Lin, Y. F., Chung, H. H. (2002). Parenting stress and parent's Willingness to accept treatment in relation to behavioral problem of children with Attention Deficit / Hyperactivity disorder. Journal of Nursing Resource, 10; 43-56.

[14] Montoya A., Colom F., Ferrin M. (2011). Is psychoeducational for parents and teachers of children and adolescent with ADHD efficacious? A systematic literature review: European psychiatry 26, 166-175.

[15] Reynolds C. R., Fletcher E. (2000). Encyclopedia of Special Education; 3; 1452.

[16] Penkman, L. (2004). Remediation of attention deficit in children: a focus on childhood cancer, traumatic brain injury and attention deficit disorder. Developmental Neurorehabilitation, 11; 125.

[17] Rappaport G. C., Ornoy A., Tenenbaum A. (1998). Is early intervention effectiveness in preventing ADHD? Isr. Psychiatry relate Sci., 35(4); 271-290.

[18] Spencer T. J. (2006). ADHD and emorbidity in childhood. Journal of Clinical Psychiatry, 67(8); 27-31.

[19] Steele M. (2004). Making The Case for Early Identification and Intervetion for Young Children at Risk for Learning Disabilities. Children Education Journal, 32(2); 75-79.

[20] Tamm L., et. al., (2009). Training and transfer effects of executive functions in preschool children. Journal of Developmental Sci., 12(1); 106.

[21] Toplak Maggie E., Laura Connors, Jill Shuster, Bojana Knezevic, Sandy Parks (2008). Review of cognitive, cognitive Behavioral, and neural-based interventions for Attention -Deficit/Hyperactivity Disorder (ADHD). Clinical psychology Review, 28; 801-823.

[22] Wender P. H. (1987). The hyperactive child, adolescent and adult. New York: Oxford University Press. 